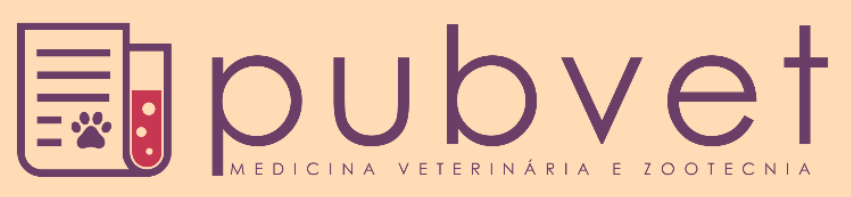

https://doi.org/10.31533/pubvet.v15n04a783.1-6

\title{
Achados laboratoriais em uma cadela com Erliquiose: Relato de caso
}

\author{
Antonio Benedito do Nascimento ${ }^{1}$, Francisca Karina Mota Ribeiro ${ }^{1}$, Belise Maria Oliveira \\ Bezerra' $^{2}$ (iD \\ IDiscente do Curso de Medicina Veterinária, Faculdade Cisne. Avenida Dr. Antonio Moreira Magalhaes,457, Estr. Do Algodao - Jardim \\ Monolitos, Quixada, Ceará, Brasil. \\ Docente do Curso de Medicina Veterinária, Faculdade Cisne, Quixada, Ceará, Brasil. \\ *Autor para correspondência,_E-mail: antoniofilho_mombaca@hotmail.com
}

Resumo: A Erliquiose canina é uma das principais doenças infecto-contagiosas, que acomete cães de todos os sexos e idades. Transmitida pelo carrapato Rhiphicephalus sanguineus, de difícil erradicação. Os cães infectados apresentam sinais inespecíficos, o que vai depender da fase em que se encontra a doença. O diagnóstico para Erliquiose pode ser realizado através da presença de mórulas nos leucócitos parasitados encontrados em esfregaços sanguíneos, alterações no hemograma, testes sorológicos ou de biologia molecular. O tratamento se baseia na utilização de antibióticos, juntamente com terapia de suporte, sendo a doxiciclina a droga de eleição. Na maioria das vezes, o prognóstico é favorável.

Palavras-chave: Doxiciclina, erliquiose, infecto-contagiosa, Rickettsia trombocitopenia

\section{Laboratory findings on a bitch with Ehrlichiosis: Case report}

\begin{abstract}
Canine Ehrlichiosis is one of the leading infectious diseases, which affects dogs of all sexes and ages. Transmitted by the Rhiphicephalus sanguineus tick, difficult to eradicate. Infected dogs show nonspecific signs, which will depend on the stage of the disease. The diagnosis for the presence of morulae in the parasitized leukocytes found in blood smears, changes in the blood count, serological tests, or molecular biology. Treatment is based on the use of antibiotics along with supportive therapy, with doxycycline being the drug of choice. Most of the time, the prognosis is favorable.
\end{abstract}

Keywords: Doxycycline, ehrlichiosis, infected dogs, Rickettsia thrombocytopenia

\section{Hallazgos de laboratorio en una perra con erlquiose: Informe del caso}

Resumen: La erliquiosis canina es una de las principales enfermedades infecciosas, que afecta a los perros de todos los sexos y edades. Transmitida por la garrapata Rhiphicephalus sanguineus, de difícil erradicación. Los perros infectados muestran signos inespecíficos, que dependerán de la etapa en que se encuentre la enfermedad. El diagnóstico de la erliquiose puede hacerse mediante la presencia de mórulas en los leucocitos parásitos que se encuentran en los frotis de sangre, los cambios en el hemograma, las pruebas serológicas o la biología molecular. El tratamiento se basa en el uso de antibióticos junto con una terapia de apoyo, siendo la doxiciclina la droga de elección. En la mayoría de los casos, el pronóstico es favorable.

Palabras clave: Doxiciclina, ericosis, infectocontagiosa, Rickettsia trombocitopenia

\section{Introdução}

A Erliquiose canina é uma doença causada por uma Rickettsia pertencente ao gênero Ehrlichia, família Rickttsiaceae, ordem Rickettsiales, gênero Ehrlichia spp., espécie Ehrlichia canis, e trata-se de 
uma bactéria Gram-negativa, intracelular obrigatória dos leucócitos (monócitos), com forma de cocobacilos e que multiplica-se por divisão binária (Birchard \& Sherding, 2008; Hagan \& Brunner, 1988; Nelson \& Couto, 2015). Microscopicamente, possui aspecto de mórulas (Jain, 1993; Mendonça et al., 2005; Nakaghi et al., 2008; Swanson, 1990), e estas permanecem na célula hospedeira por três a quatro dias para então serem liberadas com a lise celular (Birchard \& Sherding, 2008).

A transmissão da Ehrlichia canis ocorre pela inoculação de sangue proveniente de um cão contaminado para um cão sadio, pelo intermédio de um vetor, o carrapato Rhiphicephalus sanguineus (Alves et al., 2005; Birchard \& Sherding, 2008), também conhecido como o carrapato marrom do cão (Jain, 1993; Oriá, 2001), a transmissão pode ocorrer, ainda, através de transfusão sanguínea ou agulha e instrumentais contaminados com sangue (Dagnone et al., 2009).

A erliquiose ocorre em três fases: inicia-se com a fase aguda, que tem duração de uma a quatro semanas, e cujo os principais sinais são linfadenopatia, esplenomegalia, hepatomegalia, trombocitopenia e anemia. Segue-se a fase subclínica, que pode durar meses ou até anos, na qual nota-se uma aparente melhora em relação a fase anterior, com sinais clínicos discretos. Posteriormente, o organismo pode eliminar bactéria ou ela pode persistir no interior da célula e levar à fase crônica da infecção (Chiari, 2010; Jericó et al., 2015),sendo esta fase a mais severa, caracterizada por hipoplasia de medula óssea, o que resulta desde uma anemia aplásica até uma pancitopenia (Birchard \& Sherding, 2008; Nelson \& Couto, 2015).

A severidade da doença vai depender da idade do animal, alimentação, susceptibilidade racial, de doenças concomitantes e da virulência da cepa infectante (Silva et al., 2010). Segundo Isola et al. (2012), a erliquiose acomete animais de todas as idades, independente de sexo ou raça. O diagnóstico depende das diferentes fases e das múltiplas manifestações clínicas da doença. Quando houver histórico compatível, sinais clínicos, características hematológicas e anormalidades bioquímicas típicas da doença, deve-se suspeitar de erliquiose monolítica canina (Harrus \& Waner, 2011).

O diagnóstico da Erliquiose canina pode ser realizado através da presença de mórulas nos leucócitos parasitados encontrados na avaliação de esfregaços sanguíneos (Garcia et al., 2008; Machado, 2004; Moreira et al., 2005; Nakaghi et al., 2008), por testes de biologia molecular, como a reação em cadeia da polimerase (PCR) (Alves et al., 2005; Nakaghi et al., 2008) e ainda outros testes, como os de sorologia do tipo ELISA, ou ainda pela técnica de imunofluorescência indireta (IFI) de anticorpos, que consiste em uma técnica sensível, que detecta anticorpos anti - Ehrlichia canis, através do soro do sangue do animal e hoje é a mais utilizada em todo o mundo (Nakaghi et al., 2008; Oriá, 2001).

Como tratamento, existem algumas drogas empregadas por hospitais e clínicas veterinárias no Brasil para esse fim, tais como a tetraciclina, oxitetraciclina, doxiciclina e dipropionato de imidocarb. Destas drogas, a tetraciclina e seus derivados são mais amplamente empregados. A doxiciclina é a droga de eleição nos casos de pacientes que apresentam afecções renais (Andereg \& Passos, 1999; Machado, 2004).

O prognóstico depende da fase em que a doença foi diagnosticada e do início da terapia. Quanto antes se inicia o tratamento nas fases agudas, melhor o prognóstico. Nos cães, no início da doença, observa-se melhora do quadro em 24 a 48 horas, após o início da terapia (Woody \& Hoskins, 1991).

Neste trabalho iremos relatar o caso de erliquiose em uma cadela, ressaltando os achados laboratoriais.

\section{Relato de caso}

Uma cadela pinscher, de pelagem marrom, não castrada, com 7 anos de idade e pesando 2,6 kg chamada Babbí, foi levada à uma clínica veterinária na cidade de Iguatu (Ceará). O tutor relatou que o animal estava mais quieto que o normal, com dificuldade para respirar, diminuição no apetite, ingerindo menos água, urinando em menor quantidade e a urina de cor mais escura, demonstrava incômodo ao ser tocado e percebeu também o surgimento de manchas de sangue nos olhos e região abdominal.

Ao realizar o exame clínico, foi observada a presença de ectoparasitas, petéquias na região abdominal, hiposfagma, pirexia de $40,5{ }^{\circ} \mathrm{C}$, esplenomegalia, frequência cardíaca de 98 a $129 \mathrm{bpm}$, 
dispneia e mucosas hipocoradas. Diante do quadro clínico, foi solicitado testes rápido imunocromatográfico para Erlichia spp., sendo seu resultado positivo.

Desta forma, foi solicitado o hemograma, exames bioquímicos e urinálise, com objetivo de avaliar mais precisamente o quadro do animal e assim estabelecer a terapêutica.

\section{Resultados e discussão}

No resultado do eritrograma, foi observado uma diminuição na quantidade de hemácias, que se apresentam normocíticas e normocrômicas, hemoglobina e hematócrito, evidenciando assim uma discreta anemia normocítica normocrômica (Tabela 1). A anemia caracteriza-se pela redução no número de hemácias, ou no teor de hemoglobina, ou em ambas. É um reflexo de um estado patológico. A anemia ocorre em razão a uma excessiva perda de sangue (hemorragias), destruição (hemólise), ou queda na produção de eritrócitos (Birchard \& Sherding, 2008).

Tabela 1. Valores do eritrograma da cadela com erliquiose.

\begin{tabular}{lccc}
\hline Eritrograma & Valores & Unidade & Referência \\
\hline Hemácias & 5,05 & $\mathrm{x} 10^{6} / \mu \mathrm{L}$ & 6,00 a 8,00 \\
Hemoglobina & 13,20 & $\mathrm{~g} / \mathrm{dL}$ & 14,00 a 18,00 \\
Hematócrito & 38,20 & $\%$ & 40,00 a 53,00 \\
V.C.M & 69,52 & $\mathrm{fL}$ & 65,00 a 78,00 \\
C.H.C.M & 34,30 & $\%$ & 31,00 a 35,00 \\
RDW & 14,50 & $\%$ & 11,50 a 15,00 \\
Observações: & Hemácias normocíticas e normocrômicas & & \\
\hline
\end{tabular}

No leucograma, os resultados mostram que não houve alterações em relação a leucometria global, eosinófilos, neutrófilos, linfócitos e monócitos (Tabela 2). Apesar de não ter sido encontrada diferença significativa nestes parâmetros, alguns autores descreveram alterações leucocitárias importantes. Segundo Harrus et al. (1997), a monocitose é um achado frequente e é um forte indicativo da possibilidade de uma erliquiose mesmo antes da observação das mórulas. A monocitose nem sempre é observada em animais com erliquiose canina (Codner et al., 1985), em poucos animais observa-se leucopenia durante a fase aguda, estando ela presente na fase crônica da erliquiose canina (Almosny, 1998).

No plaquetograma da cadela, observou-se trombocitopenia (Tabela 2) onde, após um período de incubação de 8 a 20 dias, o agente se multiplica nos órgãos do sistema mononuclear fagocítico (fígado, baço e linfonodos). Logo, na fase aguda, a infecção acarreta hiperplasia linforreticular (Greene, 2006) com posterior inflamação (Birchard \& Sherding, 2008; Davoust, 1993).

Durante esse período, o microrganismo multiplica-se dentro das células mononucleares circulantes e dos tecidos fagocitários mononucleares do fígado, baço e linfonodos. Isso leva a linfadenomegalia e à hiperplasia linforreticular do fígado e baço. As células infectadas são transportadas pelo sangue para outros órgãos do corpo, especialmente pulmões, rins, meninges, e aderem-se ao endotélio vascular, induzindo vasculite e infecção tecidual subendotelial (Almosny et al., 2002; Ettinger \& Feldman, 2004).

Tabela 2. Valores do leucograma e plaquetograma da cadela com erliquiose.

\begin{tabular}{lcc}
\hline Leucograma/Plaquetograma & $\mathrm{x} 10^{3} / \mu \mathrm{L}$ & Valores de referência \\
\hline Leucócitos Totais & 16.630 & 8.000 a 16.000 \\
Neutrófilos & 10.233 & 4640 a 12480 \\
Segmentados & 10.233 & 4640 a 12480 \\
Bastonetes & 0 & 0 a 300 \\
Eosinófilos & 136 & 80 a 1280 \\
Basófilos & 0 & 0 a 160 \\
Linfócitos & 2.590 & 800 a 4160 \\
Monócitos & 682 & 160 a 1280 \\
Plaquetas & 132 & 250 a 500 \\
Observações: & Hemácias normocíticas e normocrômicas & \\
\hline
\end{tabular}

Secundariamente ao processo de vasculite, teremos a destruição periférica das células alvo, ou o sequestro das mesmas, levando a uma trombocitopenia e leucopenia (Buhles et al., 1975). Vale enfatizar 
que, apesar das inúmeras descrições de associações entre a trombocitopenia com cães infectados pela Ehrlichia canis, este quadro não pode ser utilizado como critério para diagnostico da ehrlichiose, pois as trombocitopenias podem se apresentar por condições causadas por outros parasitas (Sales, 2012).

Na rotina clínica, os médicos veterinários levam em consideração o valor da contagem de plaquetas, pois um dos principais sinais da erliquiose é a trombocitopenia (Jain, 1993; Mendonça et al., 2005). A trombocitopenia e anemia são encontradas geralmente em todas as fases da erliquiose, devido ao aumento de consumo das plaquetas, com sequestro esplênico e aderência da bactéria ao endotélio vascular, ocasionando uma vasculite (Mendonça et al., 2005). Além disso, mecanismos inflamatórios e imunológicos também podem causar o consumo e destruição das plaquetas (Sousa, 2006), proporcionando trombocitopenia e leucopenia (Buhles et al., 1975).

No exame bioquímico, a alanina aminotransferase (ALT) não revelou nenhuma alteração, com resultado $78 \mathrm{U} / \mathrm{L}$, e a creatinina, também apresentou índices dentro da normalidade, evidenciando o valor de $0,9 \mathrm{mg} / \mathrm{dL}$. A creatinina é mensurada com intuito de avaliar a função renal, quando aumentada, pode estar relacionada à azotemia pré-renal, principalmente nos animais com desidratação, ou ainda à glomerulonefrite, nos casos de erliquiose em que o animal já se encontra na fase crônica da doença. Quando os níveis séricos da alanina aminotransferase encontraram-se levemente elevados, pode ser justificado pelo dano hepático ou estresse sistêmico provocado pela erliquios (Almosny, 1998).

Na urinálise, observou-se discretas alterações (Tabela 3), considerando que a amostra utilizada foi a primeira urina da manhã e apresenta-se mais concentrada, foram determinados na análise física que a urina possuía um aspecto ligeiramente turvo e cor amarelo escuro, os demais parâmetros da urinálise mostraram resultados dentro da normalidade.

Tabela 3. Resultado da urinálise da cadela com Erliquiose.

\begin{tabular}{|c|c|c|}
\hline Características Físicas & & Valores de referência \\
\hline Odor & Suis generis & Suis generis \\
\hline Aspecto & Ligeiramente turvo & Límpido \\
\hline Cor & Amarelo escuro & Amarelo citrino \\
\hline $\mathrm{pH}$ & 6.5 & 5.5 a 7.5 \\
\hline Densidade & 1.03 & 1.015 a 1.045 \\
\hline \multicolumn{3}{|l|}{ Análise Bioquímica } \\
\hline Leucócitos & Ausente & Ausente \\
\hline Nitrito & Negativo & Negativo \\
\hline Urobilinogênio & Normal & Normal \\
\hline Proteínas & Ausente & Ausente \\
\hline Hemoglobina & Ausente & Ausente \\
\hline Corpos Cetônicos & Ausente & Ausente \\
\hline Bilirrubinas & Ausente & Ausente \\
\hline Glicose & Ausente & Ausente \\
\hline \multicolumn{3}{|l|}{ Sedimentoscopia } \\
\hline Células Epiteliais & Algumas & Menos 5 p/ campo \\
\hline Piócitos & $4 \mathrm{p} /$ campo & Menos 5 p/ campo \\
\hline Hemácias & Ausente & Menos 3 p/ campo \\
\hline Cilindros Leucocitários & Ausente & Ausente \\
\hline Cilindros Granulosos & Ausente & Ausente \\
\hline Cilindros Hialinos & Ausente & 0 a 2 p/ campo \\
\hline Microbiota & Normal & Normal \\
\hline Levedura & Ausente & Ausente \\
\hline Cristais de Ácido Úrico & Ausente & Ausente \\
\hline Cristais de Oxalato de Cálcio & Ausente & Ausente \\
\hline
\end{tabular}

De acordo com Tilley et al. (2008) o aspecto é estimado subjetivamente, partindo desse princípio podemos considerar que a turbidez da mesma forma que a cor, foram influenciadas pela concentração urinária. Uma amostra concentrada está mais propensa à turbidez do que uma amostra diluída.

$\mathrm{Na}$ erliquiose, o desenvolvimento das alterações renais é decorrente da deposição de imunocomplexos devido a presença do hemoparasita Ehrlichia spp. Os imunocomplexos depositam-se principalmente nos capilares da parede glomerular, provocando glomerulonefrite (Costa et al., 1973), 
associada à proteinúria (Figueiredo, 2011). Contudo, a patogênese das lesões renais devido à erliquiose canina não é bem definida (Alves et al., 2005).

Na prática clínica, a disfunção renal e suas consequências, por muitas vezes passam despercebidas entre os demais sinais clínicos e laboratoriais, devido à falta de conhecimento e necessidade de mais estudos, em relação a este assunto (Birchard \& Sherding, 2008).

Estes fatores, juntamente ao histórico do paciente, anamnese e avaliação clínica, levaram a um diagnóstico de que o animal se encontrava com erliquiose na fase aguda da doença, pois a fase subclínica é caracterizada pelo animal parecer saudável, pois os sintomas são mais brandos, podendo ocorrer leve perda de peso. É nesta fase que se observa alta concentração de anticorpos para E. canis no sangue dos cães infectados (Jain, 1993).

\section{Conclusão}

Os achados laboratoriais da cadela com erliquiose canina na fase inicial da doença indicam anemia arregerativa e trombocitopenia, sendo necessárias medidas terapêuticas que estimule a produção de hemácias e plaquetas para melhor recuperação do animal.

\section{Referências}

Almosny, N. R. P. (1998). Ehrlichia canis (Donatien \& Lestoquard, 1935): Avaliação parasitológica, hematológica e bioquímica sérica da fase aguda de cães e gatos experimentalmente infectados. Rio de Janeiro.

Almosny, N. R. P., Massard, C. L., Labarthe, N. V, O’Dwyer, L. H., Souza, A. M., Alves, L. C., \& Serrão, M. L. (2002). Hemoparasitoses em pequenos animais domésticos e como zoonoses. $1^{o}$ Edição Rio de Janeiro: LF Livros de Veterinária Ltda.

Alves, L. M., Linhares, G. F. C., Chaves, N. S. T., Monteiro, L. C., \& Linhares, D. C. L. (2005). Avaliação de iniciadores e protocolo para o diagnóstico da pancitopenia tropical canina por PCR. Ciência Animal Brasileira, 6(1), 49-54.

Andereg, P. I., \& Passos, L. M. F. (1999). Erliquiose canina: revisão. Clínica Veterinária, 4(18), 31-38.

Birchard, S. J., \& Sherding, R. G. (2008). Manual Saunders: Clínica de Pequenos Animais. In Ed. Roca (Vol. 3).

Buhles, W. C., Huxsoll, D. L., \& Hildebrandt, P. K. (1975). Tropical canine pancytopenia: Role of aplastic anaemia in the pathogenesis of severe disease. Journal of Comparative Pathology, 85(4), 511-521. https://doi.org/10.1016/0021-9975(75)90118-8

Chiari, M. F. (2010). Nova metodologia de diagnóstico para Ehrlichia canis: PCR X LAMP. Dissertação (Mestrado em Multidisciplinar) - Universidade Federal de São Carlos, São Carlos.

Codner, E. C., Roberts, R. E., \& Ainsworth, A. G. (1985). Atypical findings in 16 cases of canine ehrlichiosis. Journal of the American Veterinary Medical Association, 186(2), 166-169. http://europepmc.org/abstract/MED/3918976

Costa, J. O., Batista Jr, J. A., Silva, M., \& Guimarães, M. P. (1973). Ehrlichia canis infection in dog in Belo Horizonte, Brazil. Arq Esc Vet Bela Horizonte.

Dagnone, A. S., Souza, A. I., André, M. R., \& Machado, R. Z. (2009). Molecular diagnosis of Anaplasmataceae organisms in dogs with clinical and microscopical signs of ehrlichiosis. Revista Brasileira de Parasitologia Veterinária, 18(04), 20-25. https://doi.org/10.4322/rbpv.01804004

Davoust, B. (1993). Canine ehrlichiosis. Point Vétérinaire, 25(151), 43-51.

Ettinger, S. J., \& Feldman, E. C. (2004). Tratado de medicina interna veterinária: doenças do cão e do gato. In (5o Edição). Rio de Janeiro: Editora Guanabara Koogan S.A.

Figueiredo, M. R. (2011). Babesiose e erliquiose caninas. Trabalho Monográfico Do Curso de Pós Graduação "Lato Sensu Em Clínica Médica de Pequenos Animais, Rio de Janeiro.

Garcia, C. A., Stanziola, L., Andrade, I. C. V, Naves, J. H. F., Neves, S. M. N., \& Garia, L. A. D. (2008). Autohemoterapia maior ozonizada no tratamento de erliquiose canina-relato de caso. Congresso Brasileiro de Medicina Veterinária, 35. 
Greene, C. E. (2006). Infectious diseases of the dog and cat. (Issue Ed. 3). WB Saunders\Elsevier Science.

Hagan, W. A., \& Brunner, C. B. (1988). Microbiology and infectious diseases of domestic animals. 8ed. Cornell University Press, 951.

Harrus, S., Kass, P. H., Klement, E., \& Waner, T. (1997). Canine monocytic ehrlichiosis: a retrospective study of 100 cases, and an epidemiological investigation of prognostic indicators for the disease. Veterinary Record, 141(14), 360-363.

Harrus, S., \& Waner, T. (2011). Diagnosis of canine monocytotropic ehrlichiosis (Ehrlichia canis): An overview. The Veterinary Journal, 187(3), 292-296. https://doi.org/10.1016/j.tvj1.2010.02.001

Isola, J. G. M. P., Cadioli, F. A., \& Nakage, A. P. (2012). Erliquiose canina - revisão de literatura. Revista Científica Eletrônica de Medicina Veterinária, 18, 1-11.

Jain, N. C. (1993). Essentials of Veterinary Hematology (1st ed.). Wiley-Blackwell.

Jericó, M. M., Kogika, M. M., \& Andrade Neto, J. P. (2015). Tratado de medicina interna de cães e gatos. Guanabara Koogan.

Machado, R. Z. (2004). Erliquiose canina. Revista Brasileira de Parasitologia Veterinária, 13, 53-57.

Mendonça, C. S., Mundim, A. V., Costa, A. S., \& Moro, T. V. (2005). Erliquiose canina: Alterações hematológicas em cães domésticos naturalmente infectados. Bioscience Journal, 21(1), 167-174.

Moreira, S. M., Machado, R., \& Passos, L. F. (2005). Detection of Ehrlichia canis in bone marrow aspirates of experimentally infected dogs. Ciência Rural, 35(4), 958-960. https://doi.org/10.1590/S0103-84782005000400038

Nakaghi, A. C. H., Machado, R. Z., Costa, M. T., André, M. R., \& Baldani, C. D. (2008). Canine ehrlichiosis: clinical, hematological, serological and molecular aspects. Ciência Rural, 38(3), 766770 .

Nelson, R., \& Couto, C. G. (2015). Medicina interna de pequenos animais. Elsevier Brasil.

Oriá, A. P. (2001). Correlação entre uveítes, achados de patologia clínica, sorológicos (Reação de imunofluorescência indireta e Dot-blot ELISA) e de anatomopatologia do bulbo do olho, em animais da espécie canina, natural e experimentalmente infectados por Ehrlichia canis. (p. 89). Dissertação (Mestrado em Cirurgia Veterinária) - Faculdade de Ciências Agrárias e Veterinárias, Universidade Estadual Paulista, Jaboticabal.

Sales, M. R. R. P. (2012). Prevalência de Ehrlichia canis pela técnica de nested-PCR e correlação com a presença de mórula e trombocitopenia em cães de Alegre-ES. Dissertação (Mestrado em Ciências Veterinárias) - Universidade Federal do Espírito Santo.

Silva, J. N., Almeida, A. B. P. F., Boa Sorte, E. C., Freitas, A. G., Santos, L. G. F., Aguiar, D. M., \& Sousa, V. R. F. (2010). Soroprevalência de anticorpos anti-Ehrlichia canis em cães de Cuiabá, Mato Grosso. Revista Brasileira de Parasitologia Veterinária, 19(02), 108-111. https://doi.org/10.4322/rbpv.01902008

Sousa, V. R. F. (2006). Avaliação clínica, morfológica, hematológica, bioquímica e biomolecular de cães naturalmente infectados por Ehrlichia canis e Anaplasma platys. 2006. $46 f$. Tese (Doutorado)Universidade Federal Rural do Rio de Janeiro, Rio de Janeiro.

Swanson, J. F. (1990). Ocular manifestations of systemic disease in the dog and cat: recent developments. Veterinary Clinics of North America: Small Animal Practice, 20(3), 849-867.

Tilley, L. P., Smith, J. R., \& Francis, W. K. (2008). Consulta veterinária em 5 minutos: Espécies canina e felina. Editora Manole.

Woody, B. J., \& Hoskins, J. D. (1991). Ehrlichial diseases of dogs. Veterinary Clinics of North America: Small Animal Practice, 21(1), 75-98.

Histórico do artigo:

Recebido: 15 de agosto, 2020.

Aprovado: 22 de setembro, 2020.

Disponível online: 23 de fevereiro, 2021.
Licenciamento: Este artigo é publicado na modalidade Acesso Aberto sob a licença Creative Commons Atribuição 4.0 (CC-BY 4.0), a qual permite uso irrestrito, distribuição, reprodução em qualquer meio, desde que o autor e a fonte sejam devidamente creditados. 